CASE REPORT

\title{
Sarcoidosis and HTLV-1 infection
}

\section{H McKee, A C Young, M Haeney}

An asymptomatic, homosexual, white man was found to have an abnormal chest $x$ ray. A presumptive diagnosis of sarcoidosis was made, but pulmonary function tests and a transbronchial biopsy were normal. He then remained asymptomatic for 10 years until he developed a progressive spastic paraparesis. At this point, antibodies to human T cell lymphotropic virus type 1 (HTLV-1) were identified in the serum and cerebrospinal fluid, and the diagnosis of HTLV-1 associated myelopathy was made, the history suggesting sexual exposure to HTLV-1 many years previously. HTLV-1 is associated with a spectrum of immune related disorders, including a pulmonary sarcoid-like syndrome. Infection with this chronic proinflammatory retrovirus should be considered in the differential diagnosis of all immune disorders in at risk individuals.

W describe an asymptomatic, homosexual, white man in whom a presumptive diagnosis of sarcoidosis was made, although pulmonary function tests and a transbronchial biopsy were normal. He remained asymptomatic for 10 years until he developed a progressive spastic paraparesis, at which time antibodies to human $\mathrm{T}$ cell lymphotropic virus type 1 (HTLV-1) were identified in the serum and cerebrospinal fluid, and the diagnosis of HTLV-1 associated myelopathy was made, the history suggesting sexual exposure to HTLV-1 many years previously.

\section{CASE REPORT}

An asymptomatic 48 year old homosexual white man had a pre-employment chest $x$ ray that showed pronounced bilateral perihilar and pulmonary midzone interstitial and alveolar shadowing (fig 1). No cause was identified in the history for the abnormal radiological appearances, and no respiratory abnormalities were found on clinical examination.

Routine haematological and biochemical indices were normal; however, the serum angiotensin converting enzyme (ACE) concentration was raised at 80 IU/litre (normal 1155). Human immunodeficiency virus (HIV-1 and HIV-2) antibody testing was negative, pulmonary function tests were normal, and transbronchial biopsy was unremarkable, with no evidence of granulomata. High resolution thoracic computerised tomography scanning demonstrated perihilar and subcarinal lymphadenopathy, with appearances of pronounced perihilar interstitial pneumonitis, in the absence of fibrosis. A presumptive diagnosis of sarcoidosis was made; the patient was treated conservatively and over the next nine years remained asymptomatic. The radiological appearances did not change and pulmonary function tests remained normal.

Ten years later he presented with difficulty in walking. On examination, there was a moderate spastic paraparesis, with disproportionately severe spasticity, the rest of the neurological examination being normal.

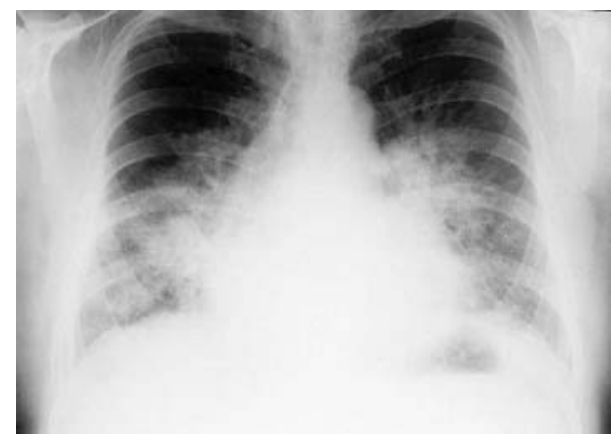

Figure 1 Chest $x$ ray showing pronounced bilateral perihilar and pulmonary midzone interstitial and alveolar shadowing.

Investigations revealed a normochromic normocytic anaemia, a raised erythrocyte sedimentation rate of $62 \mathrm{~mm} /$ hour, continuing raised serum ACE concentrations at $70 \mathrm{IU} / \mathrm{litre}$, and a polyclonal increase in serum immunoglobulins. An HIV-l antibody test was positive. The CD4 count was $320 \times 10^{6}$ cells/litre (normal, $>440$ ) and the HIV viral load was 72000 copies $/ \mathrm{ml}$. Magnetic resonance imaging of the spinal cord and brain was unremarkable. Cerebrospinal fluid (CSF) analysis revealed raised intrathecal IgG production and oligoclonal bands. A diagnosis of HIV related vacuolar myelopathy was considered, but because of his relatively immunocompetent state and the systemic inflammatory response, an alternative aetiology was sought. Further testing revealed antibodies to HTLV-l in serum and CSF, and the diagnosis of HTLV-1 associated myelopathy was made. AntiHTLV-1 antibody titres by gel particle agglutination were $1 / 512$ in CSF and $>1 / 16000$ in serum. On further questioning, the patient gave a history of episodes of unprotected sexual intercourse with an individual from a highly HTLV-1 endemic area many years previously.

\section{DISCUSSION}

HTLV-1 was the first human retrovirus to be discovered and was initially reported as causing an aggressive $\mathrm{T}$ cell leukaemia/lymphoma. ${ }^{1}$ It was subsequently shown to be the primary cause of the progressive myelopathy previously called tropical spastic paraparesis, now known as HTLV-l associated myelopathy (HAM/TSP). ${ }^{2}$ The virus is endemic in certain areas including Japan, the Caribbean, the Seychelles, and West Africa. Sporadic cases occur in Europe and the USA. Like HIV, transmission may be sexual, vertical, or via blood products. ${ }^{3}$

HTLV-1 is also associated with a spectrum of extraneural inflammatory disorders, attributed to the fact that the viral tax gene transactivates many human proinflammatory genes,

Abbreviations: $A C E$, angiotensin converting enzyme; CSF, cerebrospinal fluid; HAM, human T cell lymphotropic virus type 1 associated myelopathy; HIV, human immunodeficiency virus; HTLV-1, human T cell lymphotropic virus type 1; TSP, tropical spastic paraparesis 
Take home messages

- Human T cell lymphotropic virus type 1 (HTLV-1) is associated with a spectrum of immune disorders, including a syndrome clinically indistinguishable from sarcoidosis

- "Tropical spastic paraparesis (TSP)" is a misnomer, HTLV-1 being transmissible to any racial group and geographical area in the same manner as human immunodeficiency virus (HIV)

- HTLV-1 associated myelopathy (HAM)/TSP should be considered in the differential diagnosis of myelopathy in the relatively immunocompetent HIV positive patient

and symptomatic infection is accompanied by systemic inflammation, with a raised erythrocyte sedimentation rate and $\mathrm{C}$ reactive protein, polyclonal increase in immunoglobulins, and oligoclonal bands in serum and CSF. ${ }^{4}$ The virus has a pronounced tropism for the lung, the most common extraneural association of infection being lymphocytic alveolitis, which is reported in up to $80 \%$ of individuals with HAM/TSP and $30-60 \%$ of asymptomatic carriers. ${ }^{5}$ The radiological abnormalities include appearances very similar to those of sarcoidosis. ${ }^{6}$ Pulmonary function tests may be normal. ${ }^{67}$ Unlike sarcoidosis, there are no granulomata, and HTLV-1 proviral DNA may be isolated from bronchoalveolar lavage fluid by polymerase chain reaction. ${ }^{8}$ Other associations of HTLV-l include arthritis, hepatitis, skin rashes, sicca syndrome, and uveitis. ${ }^{5}$ A high viral load is related to the development of both HAM/TSP and the extraneural immune disorders. ${ }^{9}$

The association between HTLV-1 and sarcoidosis is complex. Clearly, given the spectrum of associated immune disorders, HTLV-1 infection may present with a syndrome very similar to sarcoid, and there are reports of cases in which sarcoidosis was diagnosed before the subsequent identification of HTLV-1 related aetiology. ${ }^{6}{ }^{10}{ }^{11}$ In addition to producing a clinical picture easily mistaken for sarcoid, a retroviral aetiology has been proposed in some cases of pathologically confirmed sarcoidosis, HTLV-1 proviral DNA having been isolated from sarcoid granulomata in the skin. ${ }^{12}{ }^{13}$

"Human T cell lymphotropic virus type 1 associated myelopathy/tropical spastic paraparesis may progress more rapidly in the presence of human immunodeficiency virus coinfection"

Although our patient presented with an illness clinically indistinguishable from sarcoidosis, the diagnosis was not confirmed histologically. Serum ACE was raised, but this is not specific for sarcoidosis, and although there are no published data on serum ACE in HAM/TSP, it is raised in patients chronically infected with HIV. ${ }^{14}$ Sarcoidosis is believed to result from an exaggerated CD4+ T cell mediated immune response to a variety of antigens. In HIV related disease, the depletion of CD4+ T cells is thought to attenuate the formation of sarcoid granulomata, particularly when the CD4 count falls to below $200 \times 10^{6}$ cells/litre. ${ }^{15}$ The association between HIV infection and symptomatic sarcoidosis was considered unusual until the introduction of highly active antiretroviral therapy and recognition of the immune reconstitution syndrome. Our patient developed a myelopathy typical of HAM/TSP, with a history of sexual exposure to HTLV-1 many years previously. He was also HIV positive and although relatively immunocompetent, HAM/TSP may progress more rapidly in the presence of HIV coinfection. ${ }^{16}$ Our case illustrates the need for awareness of HTLV-1, the risk factors for seropositivity, and the spectrum of disorders associated with this proinflammatory retrovirus. With the benefit of this knowledge at the initial presentation, it would have been useful to have performed bronchoalveolar lavage with polymerase chain reaction for HTLV-l proviral DNA, potentially enabling the diagnosis to be made earlier. Furthermore, although HIV was considered in the differential diagnosis of both clinical presentations from the outset, our patient's racial and geographical origin meant that HTLV-1 was not considered until much later.

\section{Authors' affiliations}

D H McKee, A C Young, Department of Neurology, Greater Manchester Centre for Clinical Neurosciences, Salford M6 8HD, UK

M Haeney, Department of Immunology, Hope Hospital, Stott Lane, Salford M6 8HD, UK

The patient gave his informed consent for this case report to be published.

Correspondence to: Dr D H McKee, Department of Neurology, Greater Manchester Centre for Clinical Neurosciences, Hope Hospital, Stott Lane, Salford M6 8HD, UK; david@mckee490.freeserve.co.uk

Accepted for publication 19 January 2005

\section{REFERENCES}

1 Yoshida M, Seiki M, Yamaguchi K, et al. Monoclonal integration of human Tcell leukaemia in all primary tumours of adult T-cell leukaemia suggests causative role of human T-cell leukaemia virus in the disease. Proc Natl Acad Sci U S A 1984;81:2534-7.

2 Gessain A, Bann F, Verant JC, et al. Antibodies to human T-cell lymphotropic virus type- 1 in patients with tropical spastic paraparesis. Lancet 1985;2:405-8

3 Roman GC. The neuroepidemiology of tropical spastic paraparesis. Ann Neurol 1988;23(suppl):113-20.

4 Taylor GP. Pathogenesis and treatment of HTLV-1 associated myelopathy. Sex Transm Infect 1998;74:316-22.

5 Gessain A, Gout O. Chronic myelopathy associated with human T-cell lymphotropic virus type-1. Ann Intern Med 1992;117:933-46.

6 Kikuchi T, Saijo Y, Sakai T, et al. Human T-cell lymphotropic virus type carrier with clinical manifestations characteristic of diffuse panbronchiolitis. Int Med 1996;35:305-9.

7 Setoguchi Y, Takahashi S, Nukiwa T, et al. Detection of human T-cell lymphotropic virus type-1 related antibodies in patients with lymphocytic interstitial pneumonia. Am Rev Respir Dis 1991;144:1361-5.

8 Sugimoto M, Mita S, Tokunaga M, et al. Pulmonary involvement in human Tcell lymphotropic virus type-1 uveitis: T-lymphocytosis and high proviral DNA load in bronchoalveolar lavage fluid. Eur Respir J 1993;6:938-3.

9 Osame M, Nakagawa M, Umehara F, et al. Recent studies on the epidemiology, clinical features and pathogenic mechanisms of HTLV-1 associated myelopathy (HAM/TSP) and other diseases associated to HTLV. J Neurovirol 1997;3(suppl 1):S50-1.

10 Coleman RJ, Zuckerman M, Swash M. HTLV-1 infection: the clinical spectrum widens. J Neurol Neurosurg Psychiatry 1991;54:185-6.

11 Higashiyama Y, Katamine S, Kohno S, et al. Expression of human T lymphotropic virus type $1 \mathrm{tax} / \mathrm{rex}$ gene in fresh bronchoalveolar lavage cells of HTLV-1 infected individuals. Clin Exp Immunol 1994;96:193-201.

12 Tamura N, Suzuki K, Yamamoto T, et al. Retroviral infection as a putative pathogen for sarcoidosis. Nippon Rinsho 1994;52:1503-7.

13 Yajima A, Kawada A, Aragane Y, et al. Detection of HTLV-1 proviral DNA in sarcoidosis. Dermatology 2001;203:53-6.

14 Ovellette DR, Kelly JW, Anders GT. Serum angiotensin-converting enzyme level is elevated in patients with human immunodeficiency virus infection. Arch Intern Med 1992;152:321-4.

15 Morris DG, Jasmer RM, Huang L, et al. Sarcoidosis following HIV infection. Evidence for CD4+ lymphocyte dependence. Chest 2003;124:929-35.

16 Harrison LH, Vaz B, Taveira DM, et al. Myelopathy among Brazilians coinfected with human T-cell lymphotropic virus type 1 and HIV. Neurology 1997:48:13-18. 